\title{
Assessment of fish health status in the Upper Danube River by investigation of ultrastructural alterations in the liver of barbel Barbus barbus
}

\author{
Stefanie Grund ${ }^{1, *}$, Steffen Keiter ${ }^{1}$, Melanie Böttcher ${ }^{1}$, Nadja Seitz $^{1}$, Karl Wurm $^{2}$, \\ Werner Manz ${ }^{3}$, Henner Hollert ${ }^{1,4}$, Thomas Braunbeck ${ }^{1}$ \\ ${ }^{1}$ Aquatic Ecology and Toxicology Section, Department of Zoology, University of Heidelberg, Im Neuenheimer Feld 230, \\ 69120 Heidelberg, Germany \\ ${ }^{2}$ Gewässerökologisches Labor, Tulpenstr. 4, 72181 Starzach, Germany \\ ${ }^{3}$ German Federal Institute of Hydrology, Biochemistry/Ecotoxicology, Am Mainzer Tor 1, 56068 Koblenz, Germany \\ ${ }^{4}$ Department of Ecosystem Analysis, Institute for Environmental Research, RWTH Aachen University, Worringerweg 1, \\ 52074 Aachen, Germany
}

\begin{abstract}
Despite intensive efforts and tightened guidelines for improvement of water quality over the last 2 decades, declines of fish populations have been reported for several rivers around the world. The present study forms part of a comprehensive weight-of-evidence approach, which aims to identify potential causes for the decline in fish catches observed in the Upper Danube River. The major focus of the present study is the investigation of the health status of wild barbel Barbus barbus L. collected from 3 locations along the Danube River, which experienced different levels of contamination. Whereas the comparison of the condition factor (CF) of field fish with that of control fish revealed no differences, ultrastructural investigations indicated severe disturbance of hepatic cell metabolism in field fish from the more contaminated sites Rottenacker and Ehingen, compared to both control fish and field fish from the less contaminated site Riedlingen. The ultrastructural analysis provided information about reactions of e.g. the rough endoplasmic reticulum, peroxisomes, and mitochondria, indicating an impaired health status of barbel at the sampling sites Rottenacker and Ehingen. Even though a straightforward cause-effect relationship between sediment contamination and ultrastructural alterations could not be established, based on a meta-analysis and toxicity assays it may be suggested that sediment-bound xenobiotics at least partly account for the hepatocellular changes. A relationship between impaired fish health status and the decline of fish catches along the Upper Danube River cannot be excluded.
\end{abstract}

KEY WORDS: Danube River · Fish - Population decline · Liver ultrastructure · Barbus barbus · Condition factor $\cdot$ Sediment

Resale or republication not permitted without written consent of the publisher

\section{INTRODUCTION}

An alarming number of reports about declines of fish populations in various streams around the world have been published over the past few decades (Bruton 1995, Duncan \& Lockwood 2001, de Lafontaine et al. 2002, Cook et al. 2003, Faller et al. 2003, Fu et al. 2003, Laë et al. 2004, Quirós 2004, Burkhardt-Holm et al. 2005, Keiter et al. 2006, Suski \& Cooke 2007, Sarkar et al. 2008) and have led to increasing public and scientific concern. In the Upper Danube River (southern Germany), such a decline of fish catch has been documented since the beginning of the 1990s. Despite intensive and continuous stocking programs and significant improvement of water quality since the 1970s (LFU 2004), several fish species, in particular grayling Thymallus thymallus, have been decreasing continuously (Wurm 2001, Keiter et al. 2006). In the context of 
a comprehensive weight-of-evidence approach (for design of such studies cf. Chapman \& Hollert 2006), a series of studies have been conducted over the past $5 \mathrm{yr}$ in order to identify potential factors that might be responsible for the decline in fish catches in the Upper Danube River. Within these studies, a significant ecotoxicological impact of sediments at different locations along the Danube River has been detected by both acute and mechanism-specific bioassays (Keiter et al. 2006, 2008, Otte et al. 2008, Seitz et al. 2008). However, the relevance of the detected sediment contamination for the observed fish decline has not yet been clarified.

In many cases, impairment of natural fish populations is due to immediate contaminant impacts or natural environmental stressors (e.g. temperature variation, habitat modification, sediment loading), or, more likely, the consequence of a combination of both natural and human-induced perturbations (Adams et al. 1992, Burkhardt-Holm et al. 2005). Due to the physicochemical and biological complexity of most aquatic systems, linking a specific response at higher levels of biological organization (e.g. population growth and reproduction) to contaminant-induced effects is a huge challenge (Segner \& Braunbeck 1998). In an attempt to elucidate causal relationships between effects at different levels of biological organization, the potential utility of biomarkers for monitoring both environmental quality and the health of organisms inhabiting the polluted ecosystems has received increasing attention during the last few years (Lopes et al. 2001, de la Torre et al. 2005, Mdegela et al. 2006, Minier et al. 2006). For the assessment of the consequences of waste water release and agricultural activities to fish populations in stream systems, a combination of structural indicators and biochemical biomarkers has been recommended (Adams et al. 1989, 2000, Braunbeck \& Völkl 1991, 1993, Oulmi et al. 1995, Zahn et al. 1995, 1996, Segner \& Braunbeck 1998, Hinton et al. 2001, Triebskorn et al. 2001, 2007, Castano et al. 2003). Cellular biomarkers including histopathological and ultrastructural effects represent an intermediate level of biological organization between lower-level biochemical effects and higher-level individual and population effects. These types of responses typically occur earlier than reproductive changes and are more sensitive than growth or reproductive parameters and, as integrative parameters, provide a better evaluation of organism health than a single biochemical response (Triebskorn et al. 1997, Segner \& Braunbeck 1998).

The present investigation was designed to evaluate the health status of field fish in the Upper Danube River by means of fish liver ultrastructure. Changes in liver cytology was used as a biomarker because of its central role in uptake, accumulation (Couch 1975, Gluth et al. 1985), biotransformation (Bieberstein \&
Braunbeck 1998), as well as elimination of xenobiotics (Köhler 1990). Ultrastructural investigations of liver tissue of vertebrates and invertebrates have repeatedly been shown to be useful tools to characterize the health status of organisms (Braunbeck et al. 1989, Braunbeck \& Völkl 1993, Triebskorn et al. 2001) and also provide valuable and simple measurements of degraded environmental conditions (Braunbeck et al. 1990a, Biagianti-Risbourg \& Bastide 1995, Oulmi et al. 1995, Braunbeck \& Strmac 2001, Gernhöfer et al. 2001). Fish histology may also serve as an additional line of evidence for the evaluation of the relevance of in vitro investigations for the situation in the field within complex weight-of-evidence studies (Chapman \& Hollert 2006). As an additional integrative indicator of general fish condition (Mayer et al. 1992), the condition factor (CF) was determined for each fish. Due to its benthic lifestyle and exposure to sediments, the common barbel Barbus barbus L. was selected as the test organism. The barbel has also been reported to be declining in fish catches in the Upper Danube River (Wurm 2001, Keiter et al. 2006).

The main objectives of the present study were to (1) determine the health status of field fish from different locations in the Upper Danube River, (2) determine sublethal in situ responses and elucidate whether these can be correlated with adverse effects of sediments which have been documented in vitro studies, and finally (3) consider additional information about potential causes for the fish-catch decline.

\section{MATERIALS AND METHODS}

Sampling sites. Field fish were captured by electrofishing at 3 locations along the Danube River (Fig. 1). The sampling sites were selected according to suspected differential sediment contamination, as documented by previous ecotoxicological studies at the same locations (Keiter et al. 2006, 2008, Seitz et al. 2008) and/or because of their exposure to sewage treatment plant effluents. Sediments from the Danube River at Riedlingen were considered less contaminated than those at Rottenacker and Ehingen. Control fish were taken from locations in the Rhine River (CRhine) as well as the Danube River at Riedlingen (CRiedlingen). Control fish were transferred to the laboratory and allowed to acclimate under specific conditions for at least $30 \mathrm{~d}$ in $400 \mathrm{l}$ tanks (i.e. in purified tap water, under constant aeration and a $12 \mathrm{~h}$ light: $12 \mathrm{~h}$ dark cycle at $15^{\circ} \mathrm{C}$ ). Fish were fed daily with $3 \mathrm{~mm}$ pellets of commercially available trout feed and once a week with freeze-dried chironomid larvae. To minimize variations due to age and weight differences of the samples at each location, 6 ind. with compara- 


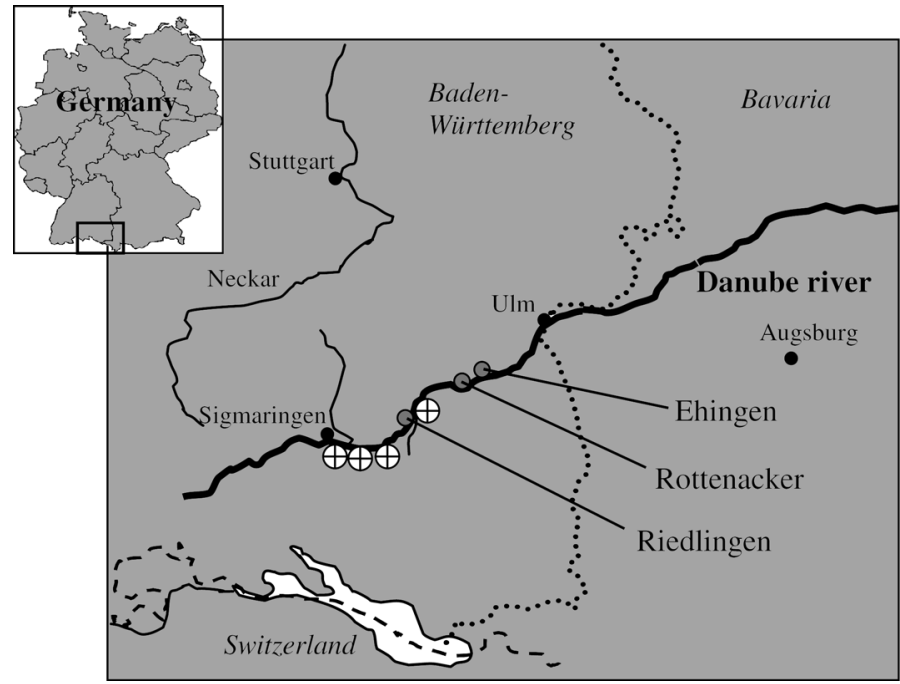

Fig. 1. Sampling sites (O) along the Danube River between Sigmaringen and Ulm. $\oplus$ : Sewage treatment plants $(>10000$ residents according to LFW 2005)

ble weight, length, and age were selected for each group.

Anesthetization and dissection. Field fish were dissected immediately upon sampling; control fish were dissected in the laboratory after appropriate periods of maintenance. Prior to dissection, fish were anesthetized by immersion in a saturated aqueous solution of ethyl-4-aminobenzoate (benzocaine; Sigma), and body weight and length were determined. To guarantee optimal fixation of the liver, fish were perfused in situ via the ventricle as described previously (Braunbeck et al. 1987). Briefly, after perfusion with ice-cold perfusion fixative (1.5\% glutardialdehyde, $1.5 \%$ formaldehyde [freshly prepared from paraformaldehyde], $2.5 \%$ polyvinylpyrrolidone [PVP] in $0.1 \mathrm{M}$ sodium phosphate buffer, $\mathrm{pH} 7.6$ ), the anterior portion of the liver was excised and transferred into perfusion fixative for at least $30 \mathrm{~min}$ at $4^{\circ} \mathrm{C}$. Liver samples were then cut into pieces of 1 to $2 \mathrm{~mm}$ length and rinsed 3 times in cacodylate buffer (0.1 M, pH 7.6). Fixation was continued in $2.5 \%$ glutardialdehyde in $0.1 \mathrm{M}$ sodium cacodylate buffer ( $\mathrm{pH}$ 7.6) containing 4\% PVP and $0.05 \%$ calcium chloride for $1 \mathrm{~h}$ at $4^{\circ} \mathrm{C}$. After duplicate rinsing in cacodylate buffer, tissue blocks were postfixed in $1 \%$ osmium ferrocyanide (Karnovsky 1971) for $2 \mathrm{~h}$ at $4^{\circ} \mathrm{C}$. After repeated rinsing in $0.1 \mathrm{M}$ cacodylate and $0.05 \mathrm{M}$ maleate buffers ( $\mathrm{pH}$ 5.2), the tissue was stained en bloc with $1 \%$ uranyl acetate in maleate buffer for at least $1 \mathrm{~h}$ at $4^{\circ} \mathrm{C}$. The specimens were dehydrated in a graded series of ethanol and embedded in Spurr's resin (Spurr 1969). Ultrathin sections of 50 to $100 \mathrm{~nm}$ thickness were stained with alkaline lead citrate (Reynolds 1963) for 2 min and examined for histo- and cytopathological alterations under a Zeiss EM 10 electron microscope.

Semi-quantitative assessment of ultrastructural alterations. To assess 'health status', ultrastructural changes in the liver were classified into the following 4 categories: \pm , without pathological findings; + , moderately developed; ++ , strongly developed; and +++ , very strongly developed. For each test group, the livers of 6 ind. (except for Site Ehingen, where only 4 fish could be caught) were studied by investigation of at least 5 sections per liver from each test specimen under the electron microscope, and the conditions of the cell organelles were assessed.

CF was calculated as $\mathrm{CF}=(W \times 100) \times L^{-3}$ with $W=$ body weight $(\mathrm{g})$ and $L=$ length (cm) (Bagenal \& Tesch (1978). One-way ANOVA followed by a Bonferroni $t$-test was used to determine significant differences between the individual fish groups. Statistical analyses were conducted using SigmaStat 3.5 (SYSTAT Software).

\section{RESULTS}

\section{Condition factor (CF)}

The mean CF of the control fish groups and of the field fish collected at 3 sampling sites of the Upper Danube River ranged from 0.69 (C-Rhine) to 0.98 (Ehingen) (Fig. 2). There were no significant differences between individual field sampling sites or

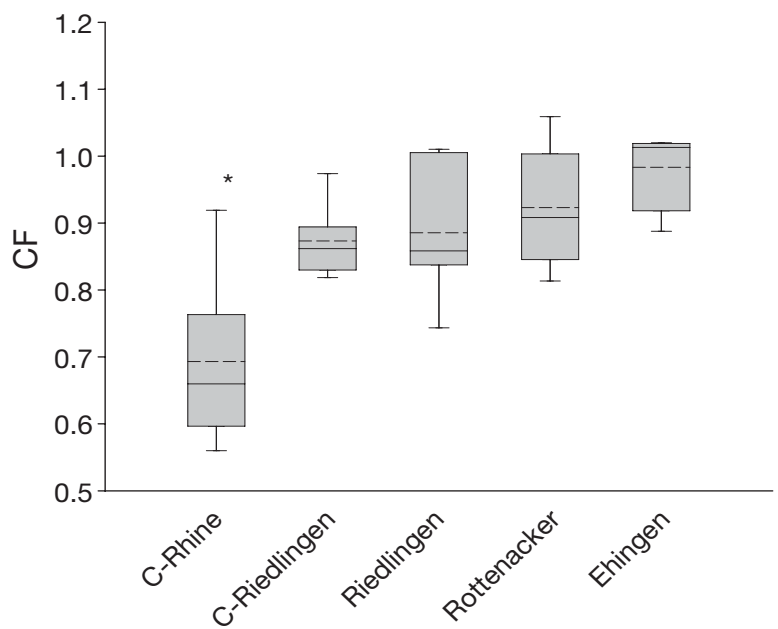

Fig. 2. Barbus barbus. Condition factor (CF) of control groups (C-Rhine and C-Riedlingen) and field fish groups (Riedlingen, Rottenacker, and Ehingen). Number of sampled fish was 4 (Ehingen) or 6 (all other groups). Data are presented as box plots indicating the median (solid line), the mean (dashed line), standard deviations (whiskers) and $25 \%$ and $75 \%$ percentiles (upper and lower limit of the shaded bar). *Significant differences between the individual fish groups and control group C-Riedlingen (1-way ANOVA, Bonferroni $t$-test; $\mathrm{p}<0.05)$ 
between sampling sites and control fish from Riedlingen; however, the mean CF of control fish from the Rhine River (C-Rhine) was significantly lower than CF values of control fish from Riedlingen (C-Riedlingen) and of all field fish groups ( $\mathrm{p}<0.05)$.

\section{Liver ultrastructure}

Alterations in liver ultrastructure were found in all field fish compared to control fish, but the prevalence and the severity differed between the individual sampling sites. A semi-quantitative evaluation of ultrastructural organization of hepatocytes from field fish compared to control fish is given in Table 1.

\section{Control fish}

The ultrastructural organization of hepatocytes of the control fish from the Rhine River as well as from the
Danube River at Riedlingen (Fig. 3) was basically identical and resembled the description of liver of control barbel Barbus barbus as described by Hugla \& Thomé (1999). Overall, the appearance of the liver of control fish showed a remarkable homogeneity between individual hepatocytes. The animals mostly displayed a compact homogeneous liver parenchyma, in which foreign cells such as macrophages were only rarely seen. Generally, the liver parenchyma comprised hepatocytes, stromal cells including endothelial cells and Ito cells, as well as extracellular spaces including the space of Disse, sinusoids, and bile canaliculi.

The hexagonal hepatocytes were characterized by a system of stacked cisternae of rough endoplasmic reticulum (RER) arranged in parallel and in the vicinity of the centrally located spherical nucleus; RER cisternae were associated with a few mitochondria and other cell organelles such as small lysosomes and peroxisomes. One to 2 Golgi fields consisting of 2 to 4 slim, short cisternae were consistently found in close proximity to the nucleus indicating low activity (low num-

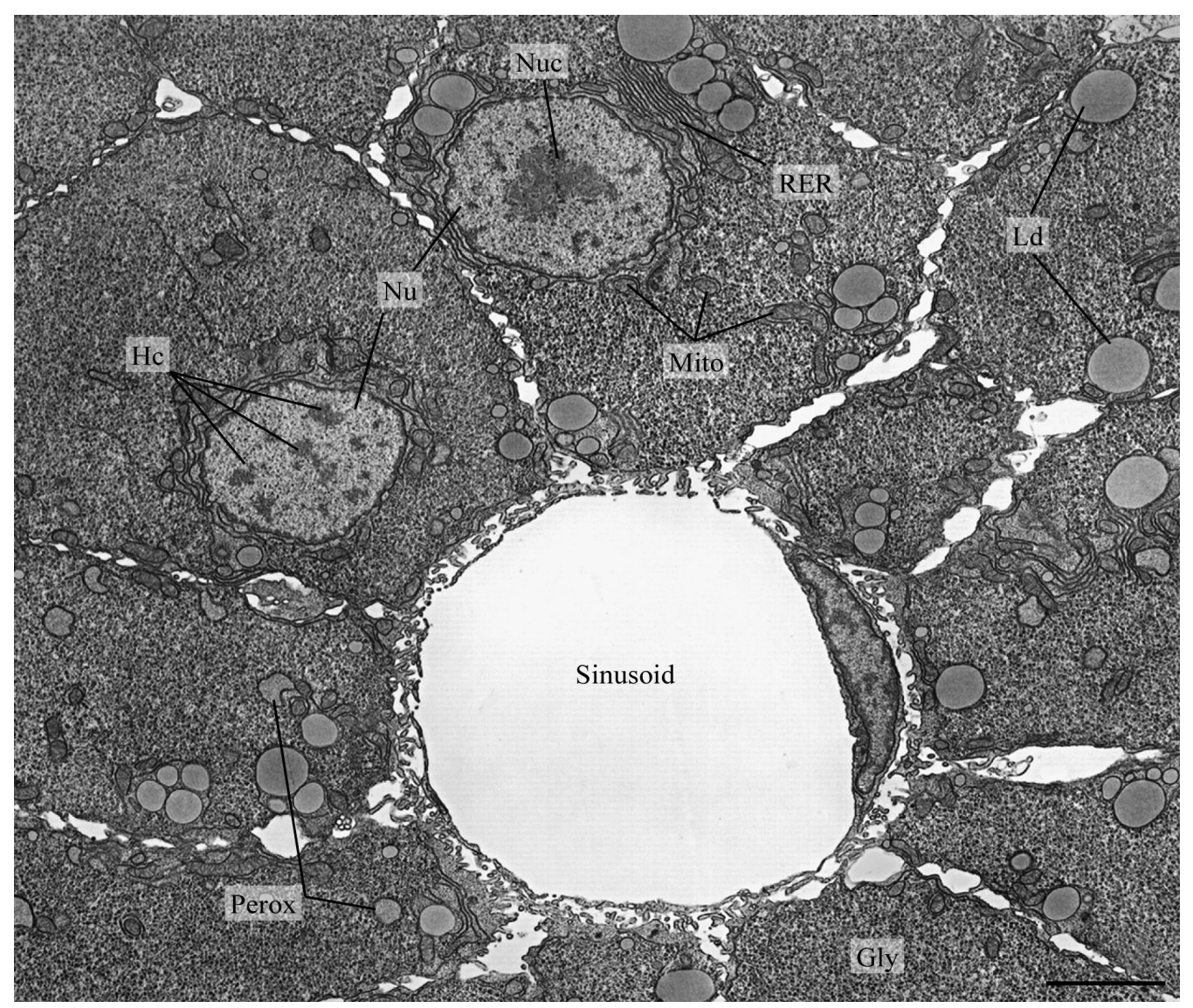

Fig. 3. Barbus barbus. Transmission electron micrograph of control fish hepatocytes. The liver is highly regular in appearance and the hepatocytes show a clear compartmentation into a central, perinuclear, and peribiliar organelle-rich area and extended peripheral cell areas with storage material mainly consisting of glycogen (Gly). Around the centrally located nucleus (Nu), few non-fenestrated lamellae of the rough endoplasmic reticulum (RER) and only a few mitochondria (Mito) and peroxisomes (Perox) can be observed. Nuc: nucleolus; Ld: lipid droplet; Hc: heterochromatin. Scale bar $=4 \mu \mathrm{m}$ 
Table 1. Barbus barbus. Semi-quantitative assessment of ultrastructural alterations in the livers of field fish compared to control fish. \pm : without pathological findings; + : moderately modified $;++$ : strongly modified $;+++$ : very strongly modified

\begin{tabular}{|c|c|c|c|}
\hline Ultrastructural alteration & Riedlingen & $\begin{array}{l}\text { Site }- \\
\text { Rottenacker }\end{array}$ & Ehingen \\
\hline \multicolumn{4}{|l|}{ Hepatocyte } \\
\hline Deformation of cell shape & + & ++ & ++ \\
\hline Disturbance of intracellular compartmentation & + & +++ & ++ \\
\hline \multicolumn{4}{|l|}{ Nucleus } \\
\hline Deformation of the nuclear envelope & +++ & ++ & \pm \\
\hline Decrease of heterochromatin & \pm & ++ & \pm \\
\hline Marginalization of heterochromatin & ++ & \pm & ++ \\
\hline Augmentation of nucleoli & +++ & +++ & \pm \\
\hline \multicolumn{4}{|l|}{ Mitochondria } \\
\hline Proliferation & + & +++ & ++ \\
\hline Increased heterogeneity in size and morphology & + & +++ & ++ \\
\hline Irregular distribution & + & +++ & +++ \\
\hline Association with RER cisternae & + & \pm & \pm \\
\hline Association with peroxisomes & + & ++ & \pm \\
\hline \multicolumn{4}{|l|}{ Peroxisomes } \\
\hline Proliferation & \pm & +++ & ++ \\
\hline Formation of clusters & \pm & +++ & + \\
\hline \multicolumn{4}{|l|}{ Rough endoplasmic reticulum } \\
\hline Proliferation & \pm & +++ & ++ \\
\hline Formation of RER stacks & \pm & ++ & ++ \\
\hline Fragmentation & \pm & + & ++ \\
\hline Dilation & \pm & +++ & + \\
\hline Vesiculation & \pm & +++ & ++ \\
\hline \multicolumn{4}{|l|}{ Smooth endoplasmic reticulum } \\
\hline Proliferation & \pm & \pm & +++ \\
\hline \multicolumn{4}{|l|}{ Golgi fields } \\
\hline Proliferation & + & ++ & ++ \\
\hline Increased secretory activity/vesicles & + & ++ & +++ \\
\hline Dilation of cisternae & \pm & +++ & ++ \\
\hline \multicolumn{4}{|l|}{ Lyosomal elements } \\
\hline Proliferation & \pm & +++ & ++ \\
\hline Heterogeneous inclusions & \pm & ++ & ++ \\
\hline Myelin-like bodies & \pm & ++ & + \\
\hline Multivesicular bodies & \pm & ++ & +++ \\
\hline \multicolumn{4}{|l|}{ Lipid droplets } \\
\hline Proliferation & \pm & ++ & \pm \\
\hline Association with mitochondria & +++ & + & ++ \\
\hline Lipid clusters & ++ & ++ & \pm \\
\hline \multicolumn{4}{|l|}{ Glycogen } \\
\hline Reduction & \pm & +++ & ++ \\
\hline Irregular density & \pm & ++ & ++ \\
\hline \multicolumn{4}{|l|}{ Additional findings } \\
\hline Increased amount of macrophages & + & +++ & +++ \\
\hline Necrotic cells & \pm & ++ & ++ \\
\hline
\end{tabular}

ber of small Golgi vesicles), and the smooth endoplasmic reticulum (SER) was only slightly developed. The cellular organization showed a clear compartmentation into a central, organelle-rich area and extended peripheral cell areas with storage materials predominantly consisting of glycogen ('intracellular compartmentation', cf. Braunbeck et al. 1990b).
Field fish from the Danube River

Riedlingen. The liver ultrastructure of field fish from Riedlingen differed only moderately from that of control animals (Fig. 4). As in control fish, hepatocytes were well-compartmentalized; lysosomes, peroxisomes, macrophages, and myelin-like bodies could 
only rarely be observed (Fig. 4a). Ultrastructural differences included elevated morphological heterogeneity of mitochondria, slightly increased numbers of RER cisternae, lipid droplets, and mitochondria, as well as a more intimate association of mitochondria with lipid droplets (Table 1, Fig. 4b,c). Furthermore, numerous hepatocytes were characterized by morphological changes of the nuclei such as pronounced deformation of the nuclear envelope, an increasing tendency of the heterochromatin to condense in the nuclear periphery, and an augmentation in the number of nucleoli (Fig. 4a).

Rottenacker. In comparison to controls, the ultrastructural organization of the liver of fish caught at Rottenacker appeared markedly altered (Fig. 5). Generally, the appearance of the liver of fish caught at Rottenacker showed a remarkable heterogeneity between individual hepatocytes (Fig. 5a). The most obvious differences were a loss of the cellular compartmentation and drastic glycogen depletion. The number of cell organelles was strongly increased, and organelles were distributed irregularly throughout the entire cytoplasm. The RER showed numerous structural alterations including proliferation, fragmentation, dilation, and vesiculation of cisternae (Fig. 5a,b,h). Mitochondria were highly heterogeneous in size and morphology (Fig. 5i), and a close association of mitochondria and peroxisomes was evident (Fig. 5f). Numerous hepatocytes displayed a deformation of cell shape as well as a deformation of the nuclear envelope. Lipid droplets and peroxisomes often accumulated to form small clusters (Fig. 5a,j). Golgi fields were characterized by an increased number of cisternae ( 5 to 6 , in contrast to 2 to 4 in controls), which were often fenestrated. Additionally, lyosomal elements (lysosomes, myelin-like bodies, vacuoles) were markedly increased in number and size in Rottenacker barbel (Fig. 5d,e). Large electron-dense secondary lysosomes were detected, mainly located close to the bile canaliculi. Further pronounced changes were increases in the numbers of macrophages (Fig. $5 \mathrm{~g}$ ) and necrotic cells (Fig. 5c) as well as an increase in the amount of moderately electron-dense, flocculent membrane-like and vesicular materials ('ghosts') in the cytoplasm as well as in the intercellular spaces (Fig. 5k).

Ehingen. Compared to the controls, the ultrastructural image of the liver of field fish from Ehingen showed conspicuous modifications (Fig. 6), which basically resembled those of field fish from Rottenacker. Alterations (that were also found in field fish from Rottenacker) included changes in the distribution and localization of organelles within hepatocytes, a distinct reduction of glycogen stores combined with a proliferation of lyosomal elements (e.g. lysosomes, myelin-like bodies, vacuoles) and other cell organelles (e.g. mitochondria, RER, Golgi fields), an elevated heterogeneity of mitochondrial size and form, an increase of membrane-like and vesicular material in the cytoplasm and in the intercellular spaces, an increase activity of the Golgi fields, and a prominent macrophage infiltration of the tissue (Fig. 6a,b,e). As a result, hepatocellular compartmentation was no longer evident, and the liver parenchyma showed conspicuous heterogeneity. Furthermore, the RER showed numerous structural alterations including proliferation, fragmentation, and vesiculation of cisternae, and transformation into concentric membrane whorls; however, this was to a lesser extent than in field fish from Rottenacker. Even though the nuclei in most cells displayed no obvious alterations, in some hepatocytes the chromatin content was completely condensed (Fig. 6d). The most conspicuous change in the livers of Ehingen barbel were increased amounts of SER, which were randomly distributed as an irregularly shaped network of branching and anastomosing cisternae between glycogen rosettes (Fig. 6b,c). A further feature specific to fish caught at Ehingen was the appearance of sizable, ovoid melanomacrophages in the intercellular spaces (Fig. 6g). Finally, numerous necrotic cells could be found between the hepatocytes (Fig. 6f).

\section{DISCUSSION}

\section{Condition factor (CF)}

Gross health indices such as the CF have been accepted as integrative indicators of general fish condition and are thought to provide information on energy reserves and possibly the ability of animals to tolerate toxicant challenges or other environmental stresses (Mayer et al. 1992). In the present study, mean CF values differed only slightly between field fish from contaminated sites and control fish from Riedlingen. Likewise, CF values of Danube fish (0.9 to 1.0) were similar to those reported for another field study with barbel (1.0 to 1.2; Flammarion \& Garric 1997). According to Bernet \& Segner (2004), a CF value of between 0.8 and 1.2 indicates no deviation from the normal status. However, the mean CF value of control fish from the Rhine River was significantly lower than that of the control fish from Riedlingen and any Danube field fish group, indicating an impaired condition of Rhine fish. For our observations, this may be due to the fact that control fish from the Rhine River behaved differently compared to control fish from Site Riedlingen during the entire period of captivity. Whereas control fish from Riedlingen adapted very rapidly to laboratory conditions, fish caught in the Rhine River consistently showed a higher sensitivity to human interference (e.g. during daily feeding, cleaning, control of water condi- 


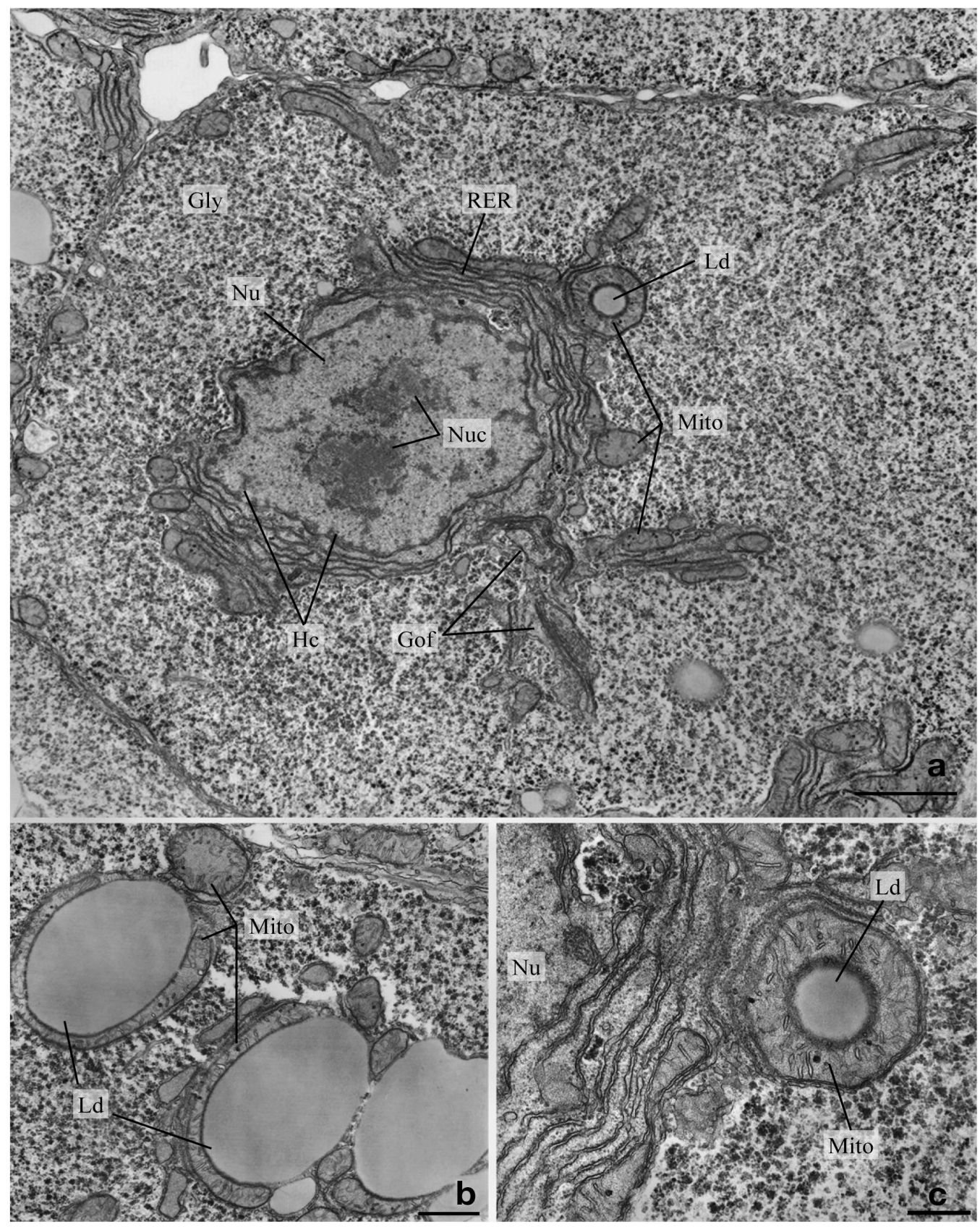

Fig. 4. Barbus barbus. Ultrastructural organization of hepatocytes of field fish from Site Riedlingen. (a) Typical hepatocyte with a clear cellular compartmentation and large peripheral amounts of glycogen (Gly). The nucleus (Nu) shows a pronounced deformation of the nuclear envelope, an increasing tendency of the heterochromatin (Hc) to condense in the nuclear periphery, and an augmentation of the number of nucleoli (Nuc). Scale bar $=2 \mu \mathrm{m} .(\mathrm{b}, \mathrm{c})$ Mitochondria (Mito) are highly heterogeneous in size and morphology and a close association of mitochondria and lipid droplets (Ld) is evident. Gof: Golgi fields; RER: rough endoplasmic reticulum. Scale bar = (a) $1 \mu \mathrm{m}$ and (b) $0.5 \mu \mathrm{m}$

tions and oxygen supply). Therefore, the lower CFs in Rhine fish may be due to reduced food uptake and increased energy consumption during elevated locomotion under stress situations.

Consequently, our results do not seem to indicate a relationship between site-specific stress and variable pollution levels. In fact, this is consistent with other field studies that failed to identify correlations between environmental pollution levels and CFs of fish (Adams 1990, Flammarion \& Garric 1997, Burkhardt-Holm \& Scheurer 2007, de la Torre et al. 2007, Hinck et al. 2007). According to Huuskonen \& Lindstroem-Seppae 


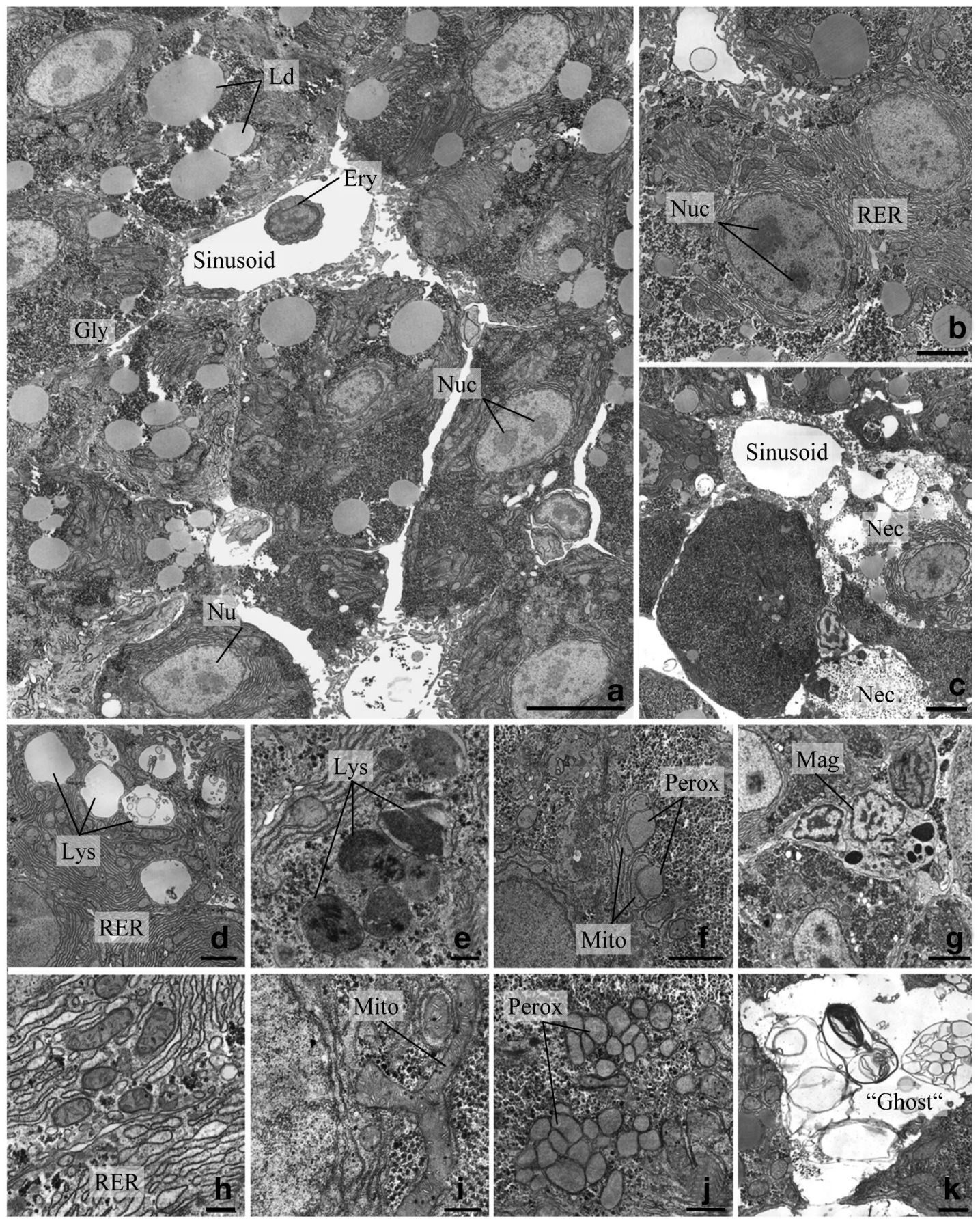

Fig. 5. Barbus barbus. Ultrastructural organization of hepatocytes of field fish from Site Rottenacker. (a) The appearance of the liver shows a remarkable heterogeneity between individual hepatocytes. The number of cell organelles is strongly increased, and organelles were distributed irregularly throughout the entire cytoplasm, resulting in a loss of cellular compartmentation. While the amount of glycogen (Gly) is significantly reduced, the number of lipid droplets (Ld) is markedly increased. Scale bar $=7 \mu \mathrm{m}$. (b) In numerous hepatocytes, the rough endoplasmic reticulum (RER) is dilated and vesiculated, and an augmentation of the number of nucleoli (Nuc) can be observed. Scale bar $=3 \mu \mathrm{m}$. (c) Necrotic cells (Nec) are frequently found in the liver parenchyma. Scale bar $=5 \mu \mathrm{m}$. (d) Proliferation of the RER and increasing numbers of large lysosomes (Lys) with membrane-like and vesicular material. Scale bar $=4 \mu \mathrm{m}$. (e) Cluster of Lys with electron-dense inclusions. Scale bar $=0.5 \mu \mathrm{m}$. (f) Close association of mitochondria (Mito) and peroxisomes (Perox). Scale bar $=1 \mu \mathrm{m}$. (g) Macrophage (Mag). Scale bar $=4 \mu \mathrm{m}$. (h) Dilated and vesiculated RER. Scale bar $=0.5 \mu \mathrm{m}$. (i) Deformation of Mito. Scale bar $=0.5 \mu \mathrm{m}$. (j) Cluster of Perox. Scale bar $=1 \mu \mathrm{m}$. (k) Moderately electrondense, flocculent membrane-like and vesicular material ('ghosts') in the intercellular space. Scale bar $=1 \mu \mathrm{m}$. Ery: erythrocyte; 

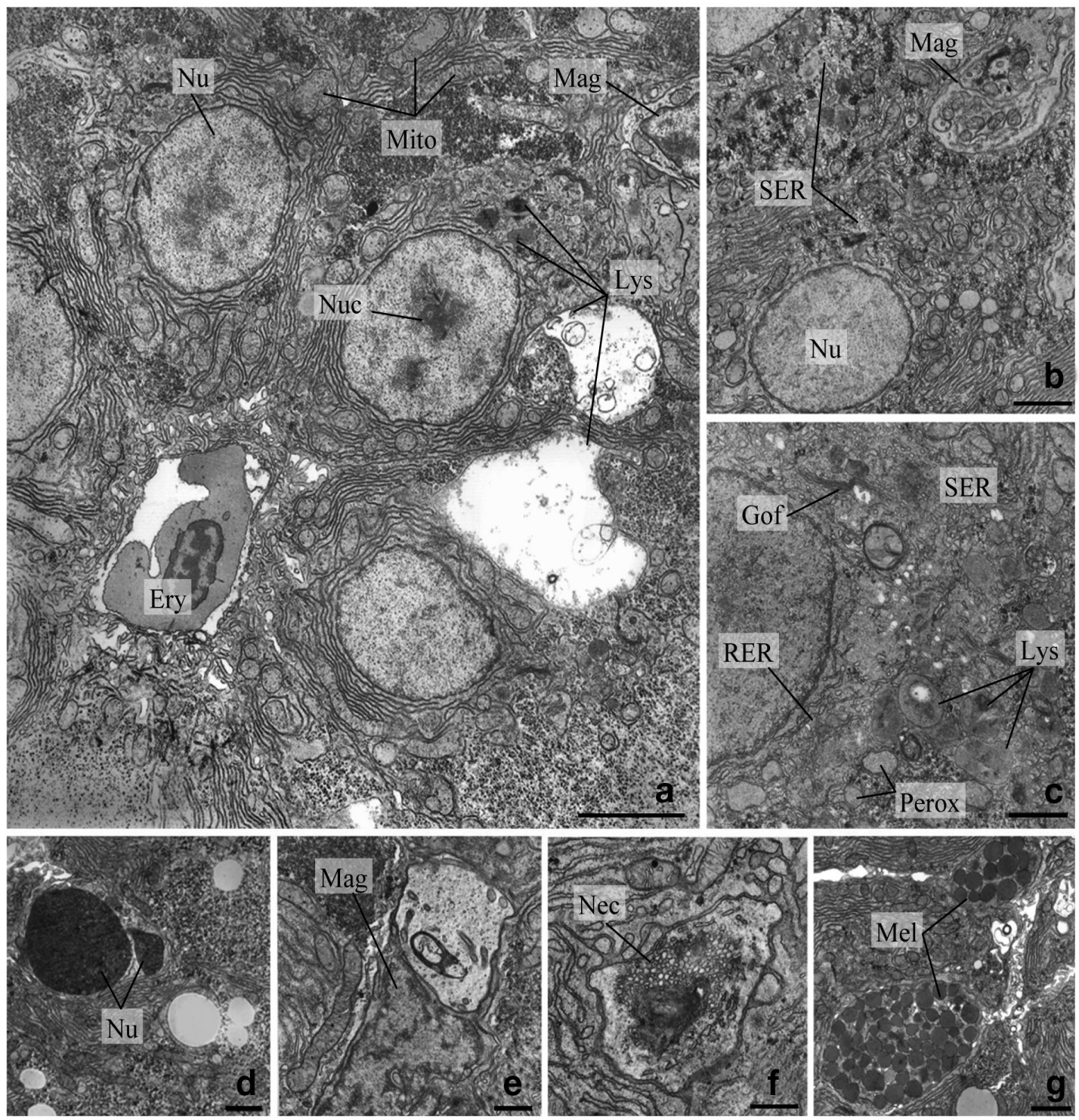

Fig. 6. Barbus barbus. Ultrastructural organization of hepatocytes of field fish from Site Ehingen. (a) The hepatocytes display a disturbed cellular compartmentation, an invasion of macrophages (Mag), and a massive decrease of storage products. The amount of organelles, e.g. rough endoplasmic reticulum (RER), smooth endoplasmic reticulum (SER), mitochondria (Mito), and lysosomes (Lys), is markedly increased. Mitochondria are highly irregular in size and shape. Scale bar $=4 \mu \mathrm{m}$. (b) In numerous hepatocytes, the amount of SER is markedly increased. The organelles are randomly distributed throughout the cell, and Mag with remnants of hepatocytes can be found. Scale bar $=2 \mu \mathrm{m}$. (c) SER can be found in intimate association with Golgi fields (Gof) as an irregularly shaped network of branching and anastomosing cisternae. Peroxisomes (Perox) display slight morphological alterations and are mostly concentrated in fields of dilated and fenestrated RER cisternae. Scale bar $=1 \mu \mathrm{m}$. (d) Split nucleus (Nu) with condensed chromatin. Scale bar $=2 \mu \mathrm{m}$. (e) Mag. Scale bar $=1 \mu \mathrm{m}$. (f) Necrotic cell $(\mathrm{Nec})$. Scale bar $=0.5 \mu \mathrm{m}$. (g) Melano-macrophages (Mel) in the intercellular space. Scale bar $=2 \mu \mathrm{m}$. Ery: erythrocyte; Nuc: nucleolus

(1995), CF values depend on the availability of nutrients in the water rather than on water pollution or other stress factors, and thus, for our investigation, it may be possible that this parameter is apparently not sensitive enough to be used as a biomarker of environmental contamination.

\section{Ultrastructural investigations}

In contrast, the ultrastructural investigations revealed conspicuous and consistent differences between control fish and field fish as well as between field fish from differently contaminated sites. Whereas modifications 
in the liver of field fish from Riedlingen were restricted to nuclear changes, liver ultrastructures of fish from Rottenacker and Ehingen were markedly altered. The most obvious ultrastructural alterations observed in the hepatocytes of field fish from Rottenacker and Ehingen were proliferation, modified structure and irregular distribution of almost any cell organelle system, as well as a drastic reduction of glycogen contents, eventually resulting in a complete loss of cellular compartmentation. Similar cellular changes were observed in several studies investigating the health status of different fish species from polluted streams (Hugla et al. 1995, Triebskorn et al. 1997, Schramm et al. 1998, Gernhöfer et al. 2001), or exposed to contaminated sediments (Wu et al. 1999) as well as various xenobiotics (Oulmi et al. 1995, Braunbeck \& Appelbaum 1999, Hugla \& Thomé 1999, Triebskorn et al. 2004, 2007).

Generally, most of the liver reactions observed can be interpreted as symptoms of elevated stress of fish during mobilization of energy reserves and as evidence of morphological restructuring in adaptation to the need for intensified metabolization/detoxification capacities (Segner \& Braunbeck 1998, Triebskorn et al. 2004). Likewise, nuclear changes such as marginalization of heterochromatin, deformation of the nuclear envelope, augmentation of nucleoli, enhanced morphological variability of mitochondria, as well as immigration of macrophages into the hepatic parenchyma also most likely represent unspecific signs of stress (Braunbeck et al. 1989, 1990a,b). The functional significance of cluster formation of peroxisomes found in hepatocytes of field fish from Rottenacker remains unclear, but has also been reported in hepatocytes of carp Cyprinus carpio after exposure to endosulfan (Braunbeck \& Appelbaum 1999).

Proliferation of lysosomes and myelin-like structures has repeatedly been interpreted as a sign of general intoxication caused by xenobiotics (Hinton et al. 1978, Braunbeck 1993) related to an increased degeneration of cell organelles (Hugla \& Thomé 1999). Alterations of the RER, including proliferation, fragmentation, and vesiculation, are common reactions to xenobiotic stress (Hacking et al. 1978, Burkhardt-Holm et al. 1999, Wu et al. 1999) and have been correlated to a higher biotransformation capacity of hepatocytes (Schoor \& Couch 1979, Braunbeck \& Völkl 1993, Au et al. 1999). Wu et al. (1999) reported proliferation of myelin figures in fish hepatocytes after $4 \mathrm{wk}$ of exposure to contaminated sediments. Proliferation of lysosomes and myelin figures has also been interpreted as a general mechanism of adaptation in response to increased degeneration of cell organelles; as a consequence, it seems logical that lysosomes and myelin numbers have also been observed in control fish hepatocytes as a function of aging (Wu et al. 1999).
Apart from these unspecific alterations, phenomena such as the proliferation of SER, which was found in the liver of fish from Ehingen, are regarded as a clear symptom of intoxication and have been associated with induction of the detoxification process of xenobiotics (Klaunig et al. 1979, Schoor \& Couch 1979, Hawkes 1980, Gingerich 1982, Hinton et al. 1987, Braunbeck et al. 1989, 1990a,c, Braunbeck \& Völkl 1991). Proliferation of SER has been found in other studies of fish exposed to organic xenobiotics (Klaunig et al. 1979, Braunbeck et al. 1990c, Arnold et al. 1996) and contaminated sediments (Wu et al. 1999). Since numerous biotransformation enzymes such as cytochrome P450 are localized on membranes of the endoplasmic reticulum and since these enzymes are involved in detoxification of many organic toxicants (Van der Weiden et al. 1989), SER proliferation has been accepted as a sensitive indicator of exposure to organic toxicants in fish.

\section{Reasons for fish decline in the Danube River}

Generally, the severity of ultrastructural modifications in the liver of fish from the Danube River reflects different levels of contamination at the 3 sampling sites. In comparable field studies, ultrastructural findings have repeatedly been shown to correspond to the degree of pollution (Hugla et al. 1995, Schramm et al. 1998, Gernhöfer et al. 2001). However, given that some of the ultrastructural alterations observed may also be induced by a whole range of 'normal' environmental factors other than contaminants such as feeding (Gas \& Pequignot 1972, Segner \& Möller 1984, Avila 1986a, 1986b) and temperature (Berlin \& Dean 1967, Braunbeck et al. 1987), it is not possible to unequivocally establish a clear cause-effect relationship between the ultrastructural alterations observed and different degrees of sediment contamination. However, since environmental factors such as availability of food and the temperature regime may be assumed to have been at least comparable between different sites along the Danube River, it is most likely that the ultrastructural changes were driven by environmental pollutants. Furthermore, liver ultrastructure as well as the CF values of control fish from Riedlingen differed only slightly from those of field fish collected from the same site. Therefore, an influence of the holding conditions of control fish compared to field fish on the liver ultrastructure can be excluded. Since most persistent contaminants tend to accumulate in sediments (Ahlf et al. 2002), it is possible that sediment contamination contributed the ultrastructural alterations observed.

Nonetheless, environmental stressors including contaminants are likely to weaken fish (Anderson \& Zeeman 1995, Rice et al. 1996, Schwaiger et al. 1997), thus 
making them more susceptible to disease or even mortality (Shul'man 1974). Hence, it seems even more reasonable to assume that the stress responses of fish from Sites Rottenacker and Ehingen are at least partly due to the relatively high sediment contamination.

Many xenobiotics tend to accumulate in the liver, making this organ particularly sensitive (Health 1995, Segner \& Braunbeck 1998). Since most lipophilic toxicants in aquatic systems preferentially bind to sediments (Ahlf et al. 2002), benthic fish species such as the barbel run an increased risk of being exposed to elevated levels of contamination than pelagic fish. For instance, barbel has been shown to be more strongly contaminated by polychlorinated biphenyls (PCBs) than salmonids and other cyprinids from the same locations (Keck \& Raffenot 1979, Vindimian et al. 1991, Hugla et al. 1995). Hugla et al. (1995) correlated alterations in liver ultrastructure similar to our observations to high PCB concentrations in barbel from the River Meuse, and PCBs have also been shown to generate a multitude of hepatic alterations in other studies (Weibel \& Paumgartner 1978, Hugla et al. 1996, Hugla \& Thomé 1999). Indeed, Keiter et al. (2008) documented considerably higher concentrations of PCBs in sediments from Sites Rottenacker and Ehingen than in those from Site Riedlingen. Although overall PCB concentrations were comparatively low, PCBs may have accumulated much more strongly in barbel via either food or direct contact with contaminated sediments.

Likewise, other studies within the weight-ofevidence approach addressing the decline of fish populations in the Upper Danube River revealed comparatively high aryl hydrocarbon receptor (AhR)mediated dioxin-like activities as well as high genotoxic potentials in sediments from Rottenacker and Ehingen (Keiter et al. 2006, 2008, Otte et al. 2008, Seitz et al. 2008). Furthermore, high concentrations of priority polycyclic aromatic hydrocarbons (PAHs) were determined in sediments from several sites along the Upper Danube River (maximum sum of 16 US EPA [Environmental Protection Agency] PAHs $26 \mu \mathrm{g} \mathrm{g}{ }^{-1}$ sediment equivalent; Keiter et al. 2008). AhR agonists such as PCBs, dibenzo- $p$-dioxins (PCDDs), dibenzofurans (PCDFs), PAHs, and polychlorinated naphthalenes (PCNs) have been documented to profoundly alter liver ultrastructure (Howard et al. 1991, Wu et al. 1999, Strmac \& Braunbeck 2002). AhR agonists like PCBs have been shown to have adverse consequences on fish health and population growth and are suspected to have been involved in several cases of fish declines (Niimi 1983, Gilbertson 1992, Monosson 1997, Fairbrother et al. 1999, Whyte et al. 2000, Van der Oost et al. 2003). However, care must be taken not to overinterpret such relationships, particularly since it is not clear which level of impairment in fish health status translates into which level of population decline, and whether the reduction in fish health status as observed at Sites Rottenacker and Ehingen is severe enough to significantly affect population growth.

\section{CONCLUSIONS}

In summary, ultrastructural investigations could be documented to be good biomarkers to characterize the health status of field fish. Even though there is no direct proof of a simple cause-effect relationship between sediment contamination and the ultrastructural alterations, it is reasonable to assume that exposure to sediment-bound xenobiotics may have resulted in adverse effects in the liver of Barbus barbus. Given that the nature and severity of the ultrastructural alterations correlate with the degree of contamination, together with results from other studies within the weight-of-evidence approach addressing the fish decline in the Upper Danube River, the ultrastructural liver changes may well be one line of evidence that sediment contamination may directly translate into adverse effects in the health status of fish and the performance of fish populations (Chapman \& Hollert 2006). Although the immediate ecological relevance of the cellular changes for the fish decline in the Upper Danube River cannot be proven, a relationship between impaired fish health status and the decline of fish populations in the Upper Danube River cannot be ruled out. As a consequence, further investigations will have to focus on (1) histo- and cytopathological studies into other organs such as gonads, kidney, and gills; (2) bioassay-directed fractionation procedures to identify the pollutants responsible for the adverse effects of sediments; and (3) the identification and quantification of concentrations of xenobiotics in field fish from the Upper Danube River.

Acknowledgements. The present study was financially supported by the research project 'Development of a statistical classification system for sediments' by the Federal Institute of Hydrology (Koblenz) and by a personal grant to S.G. by the scholarship program of the German Federal Environmental Foundation (Deutsche Bundesstiftung Umwelt [DBU]). We are particularly grateful for the support and assistance of G. Reifferscheid.

\section{LITERATURE CITED}

Adams SM (1990) Status and use of biological indicators for evaluating the effects of stress on fish. Am Fish Soc Symp 8:1-8

> Adams SM, Shepard KL, Greeley MS, Jimenez BD, Ryon MG, Shugart LR, McCarthy JF (1989) The use of bioindicators for assessing the effects of pollutant stress on fish. Mar Environ Res 28:459-464 
Adams SM, Crumby WD, Greeley MS Jr, Ryon MG, Schilling EM (1992) Relationships between physiological and fish population responses in a contaminated stream. Environ Toxicol Chem 11:1549-1557

Adams SM, Greeley MS, Ryon MG (2000) Evaluating effects of contaminants on fish health at multiple levels of biological organization: extrapolating from lower to higher levels. Hum Ecol Risk Assess 6:15-27

Ahlf W, Hollert H, Neumann-Hensel H, Ricking M (2002) A guidance for the assessment and evaluation of sediment quality: a German approach based on ecotoxicological and chemical measurements. J Soils Sediments 2:37-42

Anderson RS, Zeeman MG (1995) Immunotoxicology in fish. In: Rand G (ed) Fundamentals of aquatic toxicology: effects, environmental fate, and risk assessment. Taylor \& Francis, Washington, DC, p 371-404

Arnold H, Pluta HJ, Braunbeck T (1996) Sublethal effects of prolonged exposure to disulfoton in rainbow trout (Oncorhynchus mykiss): cytological alterations in the liver by a potent acetylcholine esterase inhibitor. Ecotoxicol Environ Saf 34:43-55

Au DWT, Wu RSS, Zhou BS, Lam PKS (1999) Relationship between ultrastructural changes and EROD activities in liver of fish exposed to benzo[a]pyrene. Environ Pollut 104:235-247

Avila EM (1986a) Evaluation of practical diets in the culture of rabbitfish, Siganus guttatus (Bloch) (Pisces: Siganidae) using liver ultrastructural methods. Zool Anz 217:178-191

Avila EM (1986b) The ultrastructure of the hepatocytes of the giant seaperch, Lates calcarifer (Bloch) (Pisces: Centropomidae), during starvation and refeeding with different diets. Asian Mar Biol 3:129-137

Bagenal TB, Tesch FW (1978) Methods for assessment of fish production in fresh waters. In: Bagenal TB (ed) Age and growth. Blackwell Scientific Publications, Oxford, p 101-136

Berlin JD, Dean JM (1967) Temperature-induced alterations in hepatocyte structure of rainbow trout. J Exp Zool 164:117-132

Bernet D, Segner H (2004) Effektstudie: Zusammenstellung von Fischgesundheitsdaten in der Schweiz. In: FischnetzPublikation. Teilprojekt 01/19. Zentrum für Fisch- und Wildtiermedizin, Universität Bern und EAWAG, Bern/ Dübendorf

Biagianti-Risbourg S, Bastide J (1995) Hepatic perturbations induced by a herbicide (atrazine) in juvenile grey mullet Liza ramada (Mugilidae, Teleostei): an ultrastructural study. Aquat Toxicol 31:217-229

Bieberstein U, Braunbeck T (1998) Light and scanning electron microscopic cytopathology of 3,5-dichlorophenol in the permanent fish cell line RTG-2. Ecotoxicol Environ Saf 41:298-306

Braunbeck T (1993) Cytological alterations in isolated hepatocytes from rainbow trout (Oncorhynchus mykiss) exposed in vitro to 4-chloroaniline. Aquat Toxicol 25:83-110

Braunbeck T, Appelbaum S (1999) Ultrastructural alterations in the liver and intestine of carp Cyprinus carpio induced orally by ultra-low doses of endosulfan. Dis Aquat Org 36:183-200

Braunbeck T, Strmac M (2001) Assessment of water and sediment contamination in small streams by means of cytological and biochemical alterations in isolated rainbow trout (Oncorhynchus mykiss) hepatocytes. J Aquat Ecosyst Stress Recovery 8:337-354

Braunbeck T, Völkl A (1991) Induction of biotransformation in the liver of eel (Anguilla anguilla L.) by sublethal exposure to dinitro-o-cresol: an ultrastructural and biochemical study. Ecotoxicol Environ Saf 21:109-127

Braunbeck T, Völkl A (1993) Toxicant-induced cytological alterations in fish liver as biomarkers of environmental pollution? A case study on hepatocellular effects of dinitro-o-cresol in golden ide (Leuciscus idus melanotus). In: Braunbeck T, Hanke W, Segner H (eds) Fish - ecotoxicology and ecophysiology. VCH Verlagsgesellschaft, Weinheim, p 55-80

Braunbeck T, Gorgas K, Storch V, Völkl A (1987) Ultrastructure of hepatocytes in golden ide (Leuciscus idus melanotus L.; Cyprinidae: Teleostei) during thermal adaptation. Anat Embryol 175:303-313

Braunbeck T, Storch V, Nagel R (1989) Sex-specific reaction of liver ultrastructure in zebra fish after prolonged sublethal exposure to 4-nitrophenol. Aquat Toxicol 14:185-202

Braunbeck T, Burkhardt-Holm P, Storch V (1990a) Liver pathology in eels (Anguilla anguilla L.) from the Rhine river exposed to the chemical spill at Basle in November 1986. Limnol Aktuell 1:371-392

> Braunbeck T, Storch V, Bresch H (1990b) Species-specific reaction of liver ultrastructure in zebrafish (Brachydanio rerio) and trout (Salmo gairdneri) after prolonged exposure to 4-chloroaniline. Arch Environ Contam Toxicol 19:405-418

> Braunbeck T, Gorge G, Storch V, Nagel R (1990c) Hepatic steatosis in zebra fish (Brachydanio rerio) induced by long-term exposure to gamma-hexachlorocyclohexane. Ecotoxicol Environ Saf 19:355-374

> Bruton MN (1995) Have fishes had their chips? The dilemma of threatened fishes. Environ Biol Fishes 43:1-27

Burkhardt-Holm P, Scheurer K (2007) Application of the weightof-evidence approach to assess the decline of brown trout (Salmo trutta) in Swiss rivers. Aquat Sci 69:51-70

Burkhardt-Holm P, Oulmi Y, Schroeder A, Storch V, Braunbeck $\mathrm{T}$ (1999) Toxicity of 4-chloroaniline in early life stages of zebrafish (Danio rerio): II. Cytopathology and regeneration of liver and gills after prolonged exposure to waterborne 4-chloroaniline. Arch Environ Contam Toxicol $37: 85-102$

Burkhardt-Holm P, Giger W, Guttinger H, Ochsenbein U and others (2005) Where have all the fish gone? The reasons why fish catches in Swiss rivers are declining. Environ Sci Technol 39:441A-447A

Castano A, Bols N, Braunbeck T, Dierickx P and others (2003) The use of fish cells in ecotoxicology. The report and recommendations of ECVAM workshop 47. ATLA Altern Lab Anim 31:317-351

> Chapman PM, Hollert H (2006) Should the sediment quality triad become a tetrad, a pentad, or possibly even a hexad? J Soils Sediments 6:4-8

Cook PM, Robbins JA, Endicott DD, Lodge KB and others (2003) Effects of aryl hydrocarbon receptor-mediated early life stage toxicity on lake trout populations in Lake Ontario during the 20th century. Environ Sci Technol 37:3864-3877

Couch JA (1975) Histopathological effects of pesticides and related chemicals on the liver of fishes. In: Ribelin WE, Migaki G (eds) The pathology of fishes, Vol 23. University Press of Wisconsin, Madison, WI, p 559-584

de la Torre FR, Ferrari L, Salibian A (2005) Biomarkers of a native fish species (Cnesterodon decemmaculatus) application to the water toxicity assessment of a peri-urban polluted river of Argentina. Chemosphere 59:577-583

$>$ de la Torre FR, Salibian A, Ferrari L (2007) Assessment of the pollution impact on biomarkers of effect of a freshwater fish. Chemosphere 68:1582-1590

de Lafontaine Y, Gilbert NL, Dumouchel F, Brochu C and oth- 
ers (2002) Is chemical contamination responsible for the decline of the copper redhorse (Moxostoma hubbsi), an endangered fish species, in Canada? Sci Total Environ 298:25-44

Duncan JR, Lockwood JL (2001) Extinction in a field of bullets: a search for the cause in the decline of the world's freshwater fishes. Biol Conserv 102:97-105

Fairbrother A, Ankley GT, Birnbaum LS, Bradbury SP and others (1999) Reproductive and developmental toxicology of contaminants in oviparous animals. In: DiGiulio RT, Tillitt DE (eds) Reproductive and developmental effects of contaminants in oviparous vertebrates. SETAC Press, Pensacola, FL, p 283-362

Faller P, Kobler B, Peter A, Sumpter JP, Burkhardt-Holm P (2003) Stress status of gudgeon (Gobio gobio) from rivers in Switzerland with and without input of sewage treatment plant effluent. Environ Toxicol Chem 22:2063-2072

Flammarion P, Garric J (1997) Cyprinids erod activities in low contaminated rivers: a relevant statistical approach to estimate reference levels for EROD biomarker? Chemosphere 35:2375-2388

Fu C, Wu J, Chen J, Wu Q, Lei G (2003) Freshwater fish biodiversity in the Yangtze River basin of China: patterns, threats and conservation. Biodiversity Conserv 12:1649-1685

Gas N, Pequignot J (1972) Restoration of the structures of the liver cell of carps renourished by two synthetic regimes after a prolonged starvation. CR Seances Soc Biol Paris 166:446-453

> Gernhöfer M, Pawert M, Schramm M, Müller E, Triebskorn R (2001) Ultrastructural biomarkers as tools to characterize the health status of fish in contaminated streams. J Aquat Ecosyst Stress Recovery 8:241-260

Gilbertson M (1992) PCB and dioxin research and implications for fisheries research and resource management. Can J Fish Aquat Sci 49:1078-1079

Gingerich WH (1982) Hepatic toxicology in fish. In: Weber LJ (ed) Aquatic toxicology. Raven Press, New York, p 55-105

Gluth G, Freitag D, Hanke W, Kortes F (1985) Accumulation of pollutants in fish. Comp Biochem Physiol C 81:273-277

Hacking MA, Budd J, Hodson K (1978) The ultrastructure of the liver of the rainbow trout: normal structure and modifications after chronic administration of a polychlorinated biphenyl Aroclor 1254. Can J Zool 56:477-491

Hawkes JW (1980) The effects of xenobiotics on fish tissues: morphological studies. Fed Proc 39:3230-3236

Health AG (1995) Water pollution and fish physiology. CRC Lewis Publishers, Boca Raton, FL

> Hinck JE, Blazer VS, Denslow ND, Myers MS, Gross TS, Tillitt DE (2007) Biomarkers of contaminant exposure in northern pike (Esox lucius) from the Yukon River Basin, Alaska. Arch Environ Contam Toxicol 52:549-562

Hinton DE, Klauning JE, Lipsky MM (1978) PCB-induced alterations in teleost liver: a model for environmental diseases in fish. Mar Fish Rev 40:47-50

> Hinton DE, Lantz RC, Hampton JA, McCuskey PR, McCuskey RS (1987) Normal versus abnormal structure: considerations in morphological responses of teleosts to pollutants. Environ Health Perspect 71:139-146

Hinton DE, Segner H, Braunbeck T (2001) Toxic responses of the liver. In: Schlenk D, Benson WH (eds) Target organ toxicity in marine and freshwater teleosts. Taylor \& Francis, London, p 224-268

Howard MO, Schwartz LW, Newton JF, Qualls CW Jr, Yodis LA, Ventre JR (1991) Comparative biochemical and morphometric changes associated with induction of the hepatic mixed function oxidase system in the rat. Toxicol Pathol 19:115-122
Hugla JL, Thomé JP (1999) Effects of polychlorinated biphenyls on liver ultrastructure, hepatic monooxygenases, and reproductive success in the barbel. Ecotoxicol Environ Saf 42:265-273

Hugla JL, Philippart JC, Kremers P, Goffinet G, Thomé JP (1995) PCB contamination of the common barbel, Barbus barbus (Pisces, Cyprinidae), in the River Meuse in relation to hepatic monooxygenase activity and ultrastructural liver change. Neth J Aquat Ecol 29:135-145

Hugla JL, Goffinet G, Kremers P, Dubois M, Lambert V, Stouvenakers N, Thome JP (1996) Ultrastructural modifications in cultured fetal quail hepatocytes exposed to pesticides and PCBs. Ecotoxicol Environ Saf 34:145-155

> Huuskonen S, Lindstroem-Seppae P (1995) Hepatic cytochrome P4501A and other biotransformation activities in perch (Perca fluviatilis): the effects of unbleached pulp mill effluents. Aquat Toxicol 31:27-41

Karnovsky MJ (1971) Use of ferrocyanide-reduced osmium tetroxide in electron microscopy. J Cell Biol 51:284

- Keck G, Raffenot J (1979) Chemical contamination by PCBs in the fishes of a French river: the Furans (Jura). Bull Environ Contam Toxicol 21:689-696

Keiter S, Rastall A, Kosmehl T, Wurm K, Erdinger L, Braunbeck T, Hollert H (2006) Ecotoxicological assessment of sediment, suspended matter and water samples in the upper Danube River. A pilot study in search for the causes for the decline of fish catches. Environ Sci Pollut Res Int 13:308-319

- Keiter S, Grund S, van Bavel B, Hagberg J and others (2008) Activities and identification of aryl hydrocarbon receptor agonists in sediments from the Danube river. Anal Bioanal Chem 390:2009-2019

Klaunig JE, Lipsky MM, Trump BF, Hinton DE (1979) Biochemical and ultrastructural changes in teleost liver following subacute exposure to PCB. J Environ Pathol Toxicol 2:953-963

Köhler A (1990) Identification of contaminant-induced cellular and subcellular lesions in the liver of flounder (Platychthys flesus L.) caught at different polluted estuaries. Aquat Toxicol 16:271-294

Laë R, Williams S, Malam Massou A, Morand P, Mikolasek O (2004) Review of the present state of the environment, fish stocks and fisheries of the River Niger (West Africa). In: Welcomme R, Petr T (eds) Proc 2nd Int Symp Management of Large Rivers for Fisheries, 11-14 February 2003, Phnom Penh, Vol I. RAP Publication 2004/16. FAO Regional Office for Asia and the Pacific, Bangkok, p 199-227

LFU (2004) Beschaffenheit der Fließgewässer. Jahresdatenkatalog 1972-2004 und aktueller Gütebericht 2004 (CD-ROM). Landesanstalt für Umweltschutz Baden-Württemberg, Karlsruhe

LFW (2005) Bericht zur Bestandsaufnahme für das Deutsche Donaugebiet. Landesamt für Wasserwirtschaft, Munich

> Lopes PA, Pinheiro T, Santos MC, da Luz Mathias M, Collares-Pereira MJ, Viegas-Crespo AM (2001) Response of antioxidant enzymes in freshwater fish populations (Leuciscus alburnoides complex) to inorganic pollutants exposure. Sci Total Environ 280:153-163

Mayer FL, Versteeg DJ, McKee MJ, Folmar LC, Graney RL, McCume DC, Rattner BA (1992) Metabolic products as biomarkers. In: Huggett RJ, Kimerly RA, Mehrle PM, Bergman HL (eds) Biomarkers: biochemical, physiological and histological markers of anthropogenic stress. Lewis Publishers, Chelsea, MI, p 5-86

Mdegela R, Myburgh J, Correia D, Braathen M and others (2006) Evaluation of the gill filament-based EROD assay in African sharptooth catfish (Clarias gariepinus) as a moni- 
toring tool for waterborne PAH-type contaminants. Ecotoxicology 15:51-59

Minier C, Abarnou A, Jaouen-Madoulet A, Le Guellec AM, Tutundjian R, Bocquene G, Leboulenger F (2006) A pollution-monitoring pilot study involving contaminant and biomarker measurements in the Seine Estuary, France, using zebra mussels (Dreissena polymorpha). Environ Toxicol Chem 25:112-119

Monosson E (1997) Reproductive and developmental effects of contaminants in fish populations: establishing cause and effect. In: Rolland RM, Gilbertson M, Peterson RE (eds) Chemically induced alterations in functional development and reproduction of fishes. SETAC Press, Pensacola, FL, p 177-194

Niimi AJ (1983) Biological and toxicological effects of environmental contaminants in fish and their eggs. Can J Fish Aquat Sci 40:306-312

Otte JC, Abrahamson A, Andersson C, Engwall M and others (2008) Induction of ethoxyresorufin- $O$-deethylase (EROD) in the three-spined stickleback (Gasterosteus aculeatus, L.) exposed to extracts of sediments from the Danube River. Environ Int 34:1176-1184

> Oulmi Y, Negele RD, Braunbeck T (1995) Cytopathology of liver and kidney in rainbow trout Oncorhynchus mykiss after long-term exposure to sub-lethal concentrations of linuron. Dis Aquat Org 21:35-52

Quirós R (2004) The Plata River Basin: international basin development and riverine fisheries. In: Welcomme R, Petr $\mathrm{T}$ (eds) Proc 2nd Int Symp Management of Large Rivers for Fisheries, 11-14 February 2003, Phnom Penh, Vol I. RAP Publication 2004/16. FAO Regional Office for Asia and the Pacific, Bangkok, p 253-271

Reynolds ES (1963) The use of lead citrate at high $\mathrm{pH}$ as an electron-opaque stain in electron microscopy. J Cell Biol $17: 208-212$

Rice CD, Kergosien DH, Adams SM (1996) Innate immune function as a bioindicator of pollution stress in fish. Ecotoxicol Environ Saf 33:186-192

Sarkar UK, Pathak AK, Lakra WS (2008) Conservation of freshwater fish resources of India: new approaches, assessment and challenges. Biodivers Conserv 17:2495-2511

Schoor WP, Couch JA (1979) Correlation of mixed-function oxidase activity with ultrastructural changes in the liver of a marine fish. Cancer Biochem Biophys 4:95-103

Schramm M, Müller E, Triebskorn R (1998) Brown trout (Salmo trutta $f$. fario) liver ultrastructure as a biomarker for assessment of small stream pollution. Biomarkers 3: 93-108

Schwaiger J, Wanke R, Adam S, Pawert M, Honnen W, Triebskorn R (1997) The use of histopathological indicators to evaluate contaminant-related stress in fish. J Aquat Ecosyst Stress Recovery 6:75-86

Segner H, Braunbeck T (1998) Cellular response profile to chemical stress. In: Schüürmann G, Markert B (eds) Ecotoxicology: ecological fundamentals, chemical exposure, and biological effects. Wiley-Liss, New York, p 521-569

Segner H, Möller H (1984) Electron microscopical investigations on starvation-induced liver pathology in flounders Platichthys flesus. Mar Ecol Prog Ser 19:193-196

Seitz N, Bottcher M, Keiter S, Kosmehl T, Manz W, Hollert H, Braunbeck T (2008) A novel statistical approach for the evaluation of comet assay data. Mutat Res 652:38-45

Shul'man GE (1974) Life cycles of fish. Physiology and biochemistry. Wiley \& Sons, New York

Spurr AR (1969) A low-viscosity exposy resin embedding medium for electron microscopy. J Ultrastruct Res 26:31-43
Strmac M, Braunbeck T (2002) Cytological and biochemical effects of a mixture of 20 pollutants on isolated rainbow trout (Oncorhynchus mykiss) hepatocytes. Ecotoxicol Environ Saf 53:293-304

Suski CD, Cooke SJ (2007) Conservation of aquatic resources through the use of freshwater protected areas: opportunities and challenges. Biodivers Conserv 16:2015-2029

Triebskorn R, Koehler HR, Honnen W, Schramm M, Adams SM, Müller EF (1997) Induction of heat shock proteins, changes in liver ultrastructure, and alterations of fish behavior: are these biomarkers related and are they useful to reflect the state of pollution in the field? J Aquat Ecosyst Stress Recovery 6:57-73

Triebskorn R, Bohmer J, Braunbeck T, Honnen W and others (2001) The project VALIMAR (VALIdation of bioMARkers for the assessment of small stream pollution): objectives, experimental design, summary of results, and recommendations for the application of biomarkers in risk assessment. J Aquat Ecosyst Stress Recovery 8:161-178

> Triebskorn R, Casper H, Heyd A, Eikemper R, Koehler HR, Schwaiger J (2004) Toxic effects of the non-steroidal antiinflammatory drug diclofenac. Part II: cytological effects in liver, kidney, gills and intestine of rainbow trout (Oncorhynchus mykiss). Aquat Toxicol 68:151-166

- Triebskorn R, Casper H, Scheil V, Schwaiger J (2007) Ultrastructural effects of pharmaceuticals (carbamazepine, clofibric acid, metoprolol, diclofenac) in rainbow trout (Oncorhynchus mykiss) and common carp (Cyprinus carpio). Anal Bioanal Chem 387:1405-1416

- Van der Oost R, Beyer J, Vermeulen NPE (2003) Fish bioaccumulation and biomarkers in environmental risk assessment: a review. Environ Toxicol Pharmacol 13:57-149

Van der Weiden MEJ, Craane LHJ, Evers EHG, Kooke RMM, Olie K, Seinen W, Van den Berg M (1989) Bioavailability of PCDDs and PCDFs from bottom sediments and some associated biological effects in the carp (Cyperinus carpio). Chemosphere 19:1009-1016

> Vindimian E, Namour P, Migeon B, Garric J (1991) In situ pollution induced cytochrome P450 activity of freshwater fish: barbel (Barbus barbus), chub (Leuciscus cephalus) and nase (Chondrostoma nasus). Aquat Toxicol 21:255-266

Weibel ER, Paumgartner D (1978) Morphological changes associated with enzyme induction. In: Estabrook RW, Lindenlaub E (eds) The induction of drug metabolism. Schattauer Verlag, Stuttgart, p 147-159

Whyte JJ, Jung RE, Schmitt CJ, Tillit DE (2000) Ethoxyresorufin- $O$-deethylase (EROD) activity in fish as a biomarker of chemical exposure. Crit Rev Toxicol 30:347-570

Wu WZ, Zhou BS, Xu Y, Schramm K, Kettrup A (1999) Cytological and biochemical alterations in Carassius auratus hepatocytes from exposure to sediment containing dioxins and related compounds. Arch Environ Contam Toxicol 37:358-363

Wurm K (2001) Untersuchung zum Rückgang des fischereilichen Ertrages in der Donau zwischen Sigmaringen und Erbach. Gewässerökologisches Labor Dr. Karl Wurm, Tübingen

Zahn T, Hauck C, Holzschuh J, Braunbeck T (1995) Acute and sublethal toxicity of seepage waters from garbage dumps to permanent cell lines and primary cultures of hepatocytes from rainbow trout (Oncorhynchus mykiss): a novel approach to environmental risk assessment for chemicals and chemical mixtures. Zentralbl Hyg Umweltmed 196:455-479

- Zahn T, Arnold H, Braunbeck T (1996) Cytological and biochemical response of R1 cells and isolated hepatocytes from rainbow trout (Oncorhynchus mykiss) to subacute in vitro exposure to disulfoton. Exp Toxicol Pathol 48:47-64 